\title{
DOCUMENTOS
}

\section{Conversación con Jorge Carrera Andrade}

\author{
UNa entrevista de William J. Straub
}

Las siguientes páginas perienecen a una entrevista realizada en la State University de Nueva York, en Stony Brook, L. I., el 29 de abril de 1971. La curiosidad despertada por la presencia de Carrera Andrade en las Universidades norteamericanas y el auge creciente de su poesía en los libros de crítica literaria y en las antologías preparadas por los profesores de los Estados Unidos, me inclinaron a llevar a cabo este proyecto de entrevistar el poeta en su residencia temporal de Stony Brook.

Carrera Andrade acababa de obtener un triunfo en la Universidad de Harvard con una conferencia y lectura de sus mejores poemas, en un acto cultural que se llamó "Carrera Andrade visto por sí mismo", en el cual fue presentado por el profesor Enrique Anderson Imbert. Mi visita, motivada además por el deseo de solicitar datos para una tesis doctoral, tuvo la amplia aceptación del poeta, quien contestó amablemente a todas las preguntas. Se publican ahora por primera vez con la autorización del entrevistado.

W.J.S. Quisiera saber, ¿cuál es su obra poética favorita, y por qué? J.C.A. Mi libro Hombre planetario, porque aborda los temas trascendentales del tiempo, la eternidad, la pluralidad de individuos encerrados en cada ser humano y las utopías de la felicidad terrestre y extra-terrestre. Creo que sus poemas constituyen mi mayor victoria sobre las palabras y definen mi posición ante el cosmos.

W.J.S. ¿Qué obra poética suya ha tenido más "éxito" en el mundo? J.C.A. No sé claramente lo que se llama "éxito". Si se trata de la venta en librerías de una gran cantidad de ejemplares, debo confesar que ninguna de mis obras están en ese caso. Pero en cambio, si se trata de la aceptación de la crítica y de la preferencia general, puedo señalar "Juan 
sin Cielo" y "Las armas de la luz". El primero de estos poemas ha sido recitado en los teatros de todas las capitales de América Hispana, y figura en múltiples grabaciones. La atmósfera de emoción creada por este poema fue tal, que el periodista ecuatoriano Alejandro Carrión adoptó como pseudónimo el nombre de "Juan sin Cielo" para sus artículos de prensa. En cuanto al poema "Las armas de la luz", ha sido traducido a varios idiomas. En francés, hay versiones de Fernand Verhesen y de Vincent Monteil. Verhesen llegó a editar el poema en una versión personal bilingüe con prólogo de Jean Cassou.

W.J.S. ¿Cómo explica usted el gran interés que su obra ha despertado en Francia?

J.C.A. Supongo que ese interés se debe al momento poético por el que atravesaba Francia. Los lectores de poesía reaccionaban contra una permanente actitud experimental y una profusión de escuelas arbitrarias como el "letrismo" y otras por el estilo. Mi poesía aportaba metáforas novedosas y un tono fresco y directo, vitalista, así como algo que po. demos llamar "un sabor geográfico". Los críticos dijeron que era una aportación original a la poesía de Occidente por la percepción nueva y mágica de los objetos.

W.J.S. ¿Por qué escribe y para quién?

J.C.A. En este punto hay dos preguntas y debo, por lo tanto, dar dos contestaciones. Escribo porque siento la necesidad de hacerlo. Hay momentos en que la poesía invade el mecanismo de mi conciencia y ya no puedo hacer otra cosa que ocuparme de ese huésped exigente, el poema. Los románticos y neoclásicos expresaron muy bien esto. Debemos re. cordar el verso: "¿Quién me libera del dios que me fatiga?", que escribió Olmedo. En cuanto a los destinatarios de mis poemas, debo decir que escribo para unos lectores invisibles que supongo poseen sentimientos análogos a los míos. Los hombres de todas paries del mundo tienen percepciones semejantes. Esta es la razón por la cual mis poemas han encontrado eco en diversos países.

W.J.S. ¿Está satisfecho con la crítica de su obra? ¿Ha sido certera y justa?

J.C.A. Lógicamente, toda la crítica no es bien orientada ni certera. Algunos críticos miran desde su ángulo la obra de arte y la interpretan sólo parcialmente. Otros son críticos creadores que prestan nuevas dimen. siones a la obra analizada. La crítica francesa ha sabido desentrañar el significado de mi obra poética y ubicarla certeramente.

W.J.S. ¿Su obra le parece resultado de un proceso, un desarrollo natural? ¿Hay una constante en su creación poética, a pesar de su variedad? 
J.C.A. Mi obra es el resultado de un proceso natural que se desarrolla, como si dijéramos, en círculos concéntricos, desde el pequeño mundo rural al cosmos. Desde el punto de vista del lenguaje, representa igualmente una evolución expresiva. La constante principal de mi creación poética es la exaltación de la realidad y el descubrimiento de las cosas como un camino para llegar a la unidad humana.

W.J.S. ¿Qué ha querido dejar u ofrecer a las letras hispanoamericanas, y lo ha logrado?

J.C.A. He deseado señalar a las letras hispanoamericanas, principal. mente a la poesía, la posibilidad de expresarse con dignidad, ennobleciendo las cosas pequeñas y agrandándolas como si fueran vistas por la lupa del lirismo. He buscado el camino de la transparencia y la frescura virginal del lenguaje. A la oscuridad deliberada, yo he opues:o la claridad. A la trivialidad intencional, he preferido la metáfora justa. W.J.S. ¿Puede hacer un comentario sobre sus relaciones con el vanguardismo como movimiento, en especial el ultraísmo?

J.C.A. Mis relaciones con el vanguardismo se redujeron a un ensayo que escribí sobre esta tendencia y no lo publiqué, como lo cuento en mi autobiografía El Volicán y el Colibri. Por esos días, mantenía yo correspondencia con el escritor peruano Alberto Guillén, que publicó en Ma. drid una antología de poetas jóvenes de América, donde figuraban algunos de mis poemas de esa época, con sabor ultraísta, como "Primavera \& Compañía". Sin embargo, fue muy limitada la influencia del ultraísmo en mi país, aunque leíamos con placer los poemas de Oliverio Girondo, Gerardo Diego y otros. Jorge Luis Borges contribuyó a simplificar el lenguaje poético y tuvo un bueno discípulo en Jorge Reyes. Pero, yo personalmente no tenía correspondencia con los ultraístas y andaba por otros caminos trazados por influencias de Gide y Jules Renard.

W.J.S. ¿Cuál es su opinión sobre este movimiento, el ultraísmo, y quiero saber si fue un error de la juventud, o si se aprovechó de las nuevas técnicas de la imagen y del verso?

J.C.A. El ultraísmo se originó como eco de algunas escuelas francesas de vanguardia, y fue un reflejo bastante tardío de Apollinaire, según lo confesó Borges en 1964. No fue un error de juventud, sino que constituyó una disciplina provechosa para el autor del Fervor de Buenos Aires y para otros poetas argentinos, sobre todo en la confección de la imagen y la metáfora autónomas.

W.J.S, ¿Con quién se siente más afín entre los ultraís'as, como escritor?

J.C.A. No creo tener afinidad con ningún poeta ultraísta. Me siento 
más cerca de Huidobro y del creacionismo. Alguien ha dicho que yo ocupo un lugar equidistante, equinoccial entre el intelectualismo de Bor. ges y el expresivismo intuitivo de Vallejo.

W.J.S. ¿Cree usted que el creacionismo de Huidobro marca una línea divisoria radical y fundamental en la poesía hispanoamericana?

J.C.A. Sí. En la poesía hispanoamericana se manifiesta con firmes trazos el movimiento creacionista. En México, Venezuela, Perú aparecen muchos seguidores de Huidobro. Se puede identificar la estética huidobriana en algunos poemas de Carlos Pellicer, Villaurrutia, Queremel, Parra del Riego, Alberto Hidalgo y otros. No hay un poeta del segundo cuarto del siglo $\mathrm{xx}$ que no le deba algo al creacionismo.

W.J.S. ¿Cuáles elementos más importantes del surrealismo - el juego, el sueño, el erotismo, el humor, la escritura au:omática, etc.- ha usado más?

J.C.A. No debemos confundir el creacionismo y el surrealismo. El ul. traísmo sí proviene del creacionismo, y nació en Madrid cuando Huidobro pasó por esa ciudad en 1918. Sin embargo, el creacionismo le debe mucho a Apollinaire que inventó el nombre de surrealismo para designar la poesía de la subconsciencia. En realidad, de los elcmentos que usted señala como más importantes del surrealismo, yo he usado sólo el humor, el erotismo y el metaforismo. Pero mi metáfora es distinta a la del surrealismo porque procede por analogías y no por diferencias. También, mi mundo erótico es real antes que onírico. No creo en la escritura automática, y para mí, la realidad es más cabal que el sueño, como ya lo dije en mi poema "El objeto y su sombra".

W.J.S. ¿Qué importancia tiene para usted el cubismo como procedimiento?

J.C.A. El cubismo constituyó al principio una revolución en la pintura, y luego se extendió a las otras artes plásticas. El cubimo literario tuvo pocos devotos, entre ellos Apollinaire y Blaise Cendrars. El cubismo redujo el mundo a formas geométricas pero of reció también una visión nueva de las cosas. El poeta que más reflejó la influencia del cubismo en sus obras fue Pierre Reverdy, quien fundó, con Huidobro, el creacionismo. W.J.S. ¿Cuál es el papel más importante del poeta?

J.C.A. No creo que el poeta tenga que desempeñar un papel, sino más bien que cumplir una misión: interpretar las apariencias del mundo y descifrar el lenguaje de las cosas para darles a entender a los otros hombres, contribuyendo de esta manera a que la vida humana sea digna de vivirse. El poeta no debe apartarse de la sociedad, y debe participar en su aventura. 
W.J.S. ¿El poeta debe ser, en'onces, mensajero, profeta, misionero?

J.C.A. Las tres cosas a la vez. Y otras más aún en el momento necesario. W.J.S. ¿El poeta es revelador de la realidad, transformador, o creador, cantor o conductor?

J.C.A. Ninguna de estas funciones se excluye. Creo en la misión del poeta como revelador del mundo real, revelación para la cual puede servirse de la transformación metafórica, o sea de la creación lírica. Aún sin quererlo, el poeta, al cantar, al of recer su poema conduce a los hombres que le entienden hacia un más amplio horizonte espiritual. W.J.S. Cuando se trata de la creación artística, ¿la realidad se impone, o el autor mismo?

J.C.A. La creación artística es el fruto de una doble colaboración entre el mundo de la realidad y el contemplador. Ninguno de los dos se impone. La conciencia ordena los elementos de la realidad valiéndose de los re. cursos más apropiados para presentar lo real en toda su autenticidad. W.J.S. ¿El verso claro, sencillo, no trabajado de usted, resulta del deseo de comunicarse con una mayoría de los lectores? ¿Se debe al mensaje contenido? ¿Se debe a la urgencia, la necesidad del cambio?

J.C.A. Mi verso es claro, pero no se puede afirmar que no sea trabajado. En varias ocasiones he dicho ya que detesto la improvisación, y que mi método es el rigor reflexivo. Yo trabajo mi poesía con la finalidad de obtener la mayor fuerza expresiva. No pienso en el número de lectores que podría obtener mi poema, solamente trato de preservar su sentido y su mensaje. Nunca me apresuro en la creación de un poema, ya que jamás he sentido la urgencia de la poesía, cuyo mecanismo trabajo en el momento más inesperado con una lentitud que es la mejor garantía de su calidad.

W.J.S. ¿Fundamenta una paesía en su significado, o en el puro juego de imagen?

J.C.A. Estas dos categorías de poesía son altamente válidas. Sin embargo, mi preferencia es por la creación de un poema significativo, de un poema que imponga un significado y no sea sólo un juego estético producido por la gracia o luminosidad de una imagen.

W.J.S. ¿Debe el poema basar su estructura en una unidad temática, o en una disolución de esa unidad?

J.C. $A$. La estructura del poema que yo suelo escribir se basa siempre en la unidad temática. En mi poema, hay un eje central en torno del cual se ordenan las metáforas. La disolución de la unidad temática fue una de las características del ultraísmo.

W.J.S. El espacio y el tiempo, ¿son categorías metafísicas, o son partes 
de su acción vital, y por tanto ingrediente directo del fenómeno poético? J.C.A. El espacio y el tiempo son indudablemente categorías metafísicas. Pero yo las siento como realidades físicas, entremezcladas profun. damente al ser. El hombre está hecho de materia y de tiempo, y ocupa un lugar en el espacio. La identidad espacio-tiempo es un fenómeno vital que influye directamente sobre mi poesía. No concibo el espacio-tiempo como un laberinto, sino como una omnipresencia, como una totalidad de la que el hombre forma parte.

W.J.S. ¿Considera usted que el poeta de las últimas décadas es un solitario perdido en el mundo, y que sólo puede recrearse en el "laberinto de su soledad"?

J.C.A. El poeta de todos los tiempos ha sido un solitario. Pero, el poeta moderno es, a más de solitario, un hombre solidario de todos los grandes problemas de la humanidad.

W.J.S. Tengo la impresión de que usted comparte más bien el goce y la alegría de la creación, como en el verso de Keats: "a thing of beauty is a joy forever". ¿Es cierto?

J.C.A. Efectivamente. Mi poesía es una poesía del gozo vitalista del descubrimiento de las cosas más hermosas de la creación.

W.J.S. ¿Será la poesía un "cementerio de huesos" como dice Neruda, o será el mundo de Aurosia?

J.C.A. En el momento en que Neruda escribió su "Residencia en la tierra", el mundo era un "cementerio de huesos". Pero la humanidad desde entonces ha partido de la destrucción a la construcción de un mundo nuevo. Debemos tener esperanza en que el mundo sea una nueva Aurosia, especialmente nuestro nuevo mundo.

W.J.S. ¿Puede hablar de los recursos estilísticos que usted emplea?

J.C.A. En realidad, de una manera voluntaria y consciente, no podría decir que yo suelo usar de ciertos recursos estilísticos. Los recursos estilísticos existen en mi poesía. Se producen al crear el poema. Pero, volun. tariamente, no puedo yo señalar otros que la metáfora, la imagen, el rigor en el escogimiento del vocablo exacto que dé una sensación perfecta de la realidad.

W.J.S. ¿Podemos hablar de la diferencia que hay o que existe entre la metáfora y la imagen? Por ejemplo, Bachelard dice que, para él, la me. táfora es una cosa intelectual, que es una imagen falsa, y que la imagen consiste en, o es resultado de la imaginación pura.

J.C.A. Posiblemente se me ha escapado esta explicación de Bachelard de metáfora e imagen, pero yo creo que igualmente ambas formas de 
expresión tienen el mismo origen intelectual, tanto la metáfora como la imagen. Aclaremos: ¿Qué es lo intelectual? Lo intelectual, ¿es aquello que está separado de la conciencia? ¿Es lo subconsciente o es lo consciente? Este es el problema que deberíamos plantear para saber efectivamente cuál es la diferencia entre metáfora e imagen. Cuando dice Jean Giono, por ejemplo: "el seno verde de la colina", eso es una metáfora. Es una idea completa, una sensación visual completa. La imagen es un poco más detallada, como si dijéramos, por ejemplo: "la respiración de la colina", que implica la presencia del aire saludable y puro. Es de. cir, la imagen es una metáfora que podría desarrollarse en varios planos, en dos o tres planos.

W.J.S. Entonces, después de la metáfora, más allá viene la imagen, es una cosa más amplia.

J.C.A. Yo concibo como una cosa más amplia la imagen que la metáfora: Ahora que puede llamarse en conjunto estilo metafórico aquello que usa de la imagen y de la metáfora, porque donde existe la metáfora, ya existe una imagen. $Y$ la imagen tiene el resorte metafórico como forma de revelarse. De modo que, para mí, son dos cosas que se asemejan mucho.

W.J.S. ¿Pero la imagen sería la culminación de una metáfora?

J.C.A. Sí. Para mí, la imagen es la culminación de una metáfora, o de varias metáforas.

W.J.S. Las imágenes de usted, me parece que se hacen de, por lo menos, dos elementos. Por un lado, un elemento natural y, por otro lado, un elemento humano, social, y que las dos cosas se mezclan para formar la imagen. ¿Será cierto, o hay otros elementos? ¿Me equivoco?

J.C.A. No, yo creo que usted tiene razón. Tal vez, yo creo que una sola palabra podría servir para darnos una idea de mi trabajo metafórico. Esa palabra es humanización de la poesía, humanización de la imagen. Esta especie de humanización es la animación de las cosas, como si fueran seres humanos. Por ejemplo, usted ve en mi poema "Cuadernos de poemas indios" dice: "la loma estaba sentada en el campo con su poncho a cuadros". La loma es como un ser humano, y da una idea de una serie de cosas laterales. Por ejemplo, "con su poncho a cuadros", es decir, con el recorte marcado por los sembrados que son más o menos geométricos en el campo sudamericano. Esto da idea del trabajo humano, y quien usa el poncho es el indio, lo cual nos lleva por una especie de sistema analítico, automático a la idea de la explotación indígena y todo lo demás. $\mathrm{O}$, en otra imagen de esa época que dice: "el mar, vendedor de espejos", se atribuye al mar actitudes humanas. La naturaleza está toda 
humanizada. $Y$ es una de las características de la poesía hispanoamericana esta humanización de la naturaleza. Nosotros queremos que la naturaleza sea un poco a la medida del hombre. Y la naturaleza tiene la misma capacidad de sufrimiento y emotividad que el ser humano.

W.J.S. ¿Existe una crisis de la poesía?

J.C.A. En todas las épocas se ha hablado de una crisis poética. En nuestros años, se ha venido señalando por algunos críticos la existencia de una crisis poética y en realidad yo no la he podido palpar. En los públicos europeos, la poesía tiene una inmensa aceptación. $\mathrm{H}_{\mathrm{a}}$ habido el caso de editores que han creído correr aventura peligrosa al editat un libro y que han hecho un negocio redondo. Lo cual indica que todavia hay lectores de poesía. Esto, en lo que se refiere al público. En lo que se refiere a la crítica, es verdad que ésta ha venido buscando para ejercerse la atracción de la novela, que, como es un género mucho más leído, tiene más amplio público. Pero, en realidad, vuelvo a afirmarlo, no hay crisis poética.

W.J.S. ¿Y el futuro de la poesía hispanoamericana? ¿Cuál sería?

J.C.A. Yo no me siento profe $a$, y apenas puedo señalar algo que podría, tal vez, ser el camino del futuro en la poesía, que es la afirmación de América. El poeta tiene que volver los ojos a nuestra América, a las condiciones absolutamente reales, naturales, materiales del mundo americano, y. separarse de la tutoría de la poesía extranjera. Al hablar de poesía extranjera, un poco más claramente podría referirme a la poesía francesa y a la poesía inglesa. En los últimos tiempos, por ejemplo, hemos visto cómo la influencia inglesa ha marcado a poetas como Jorge Luis Borges y otros en América Latina. La poesía, para mí, es la culminación del estado cultural de un pueblo y debemos buscar la madurez de esa culminación en América mediante una poesía autónoma.

$W . J . S . \quad ¿ Y$ sus planes para el futuro?

J.C.A. Mis planes se reducen a un solo vocablo: escribir. No he tenido tiempo de hacerlo porque la vida me ha llevado por otros caminos. Pero, ahora creo que voy a tener el tiempo necesario para llevar a la práctica una serie de proyectos de tipo literario, entre los cuales el primer plano ocupa la poesía.

W.J.S. Otra cosa. Cuando pienso en su obra, recuerdo una cita que encontré una vez en Daudet y pensaba usarla como lema o epígrafe del trabajo que hago, y dice que "los poetas son hombres que han conservado sus ojos de niños". ¿Usted cree que sirve, que es una manera de expresar bien su punto de vista, "con los ojos de niño"?

J.C.A. Sí. Muchos autores al hablar de la poesía han dicho que es casi 
una mirada infantil sobre el universo porque dentro de la poesía hay la inocencia de la niñez, hay un candor y al mismo tiempo un deslumbra. miento de mundo descubierto por el niño. El niño comienza a descubrir la realidad que le rodea. El poeta es también un descubridor, un descubridor del mundo con una mirada virginal, o sea nueva, con una mirada nueva.

University of Pittsburgh

William J. Straub 
